\title{
Pesticides Detected in Urban Streams During Rainstorms and Relations to Retail Sales of Pesticides in King County, Washington
}

According to studies conducted in the Puget Sound Basin from 1987 to 1995 and summarized by Bortleson and Davis (1997), more types of pesticides were detected in urban streams than in agricultural streams. As well, in the Puget Sound Basin, more pounds of pesticides were applied in urban than in agricultural areas (Tetra Tech Incorporated, 1988). To provide some insight about sources of pesticides found in urban streams, the U.S. Geological Survey (USGS), the Washington State Department of Ecology, and King County collaborated to study and compare types of pesticides found in urban stream water with pesticide sales information from large home and garden stores.

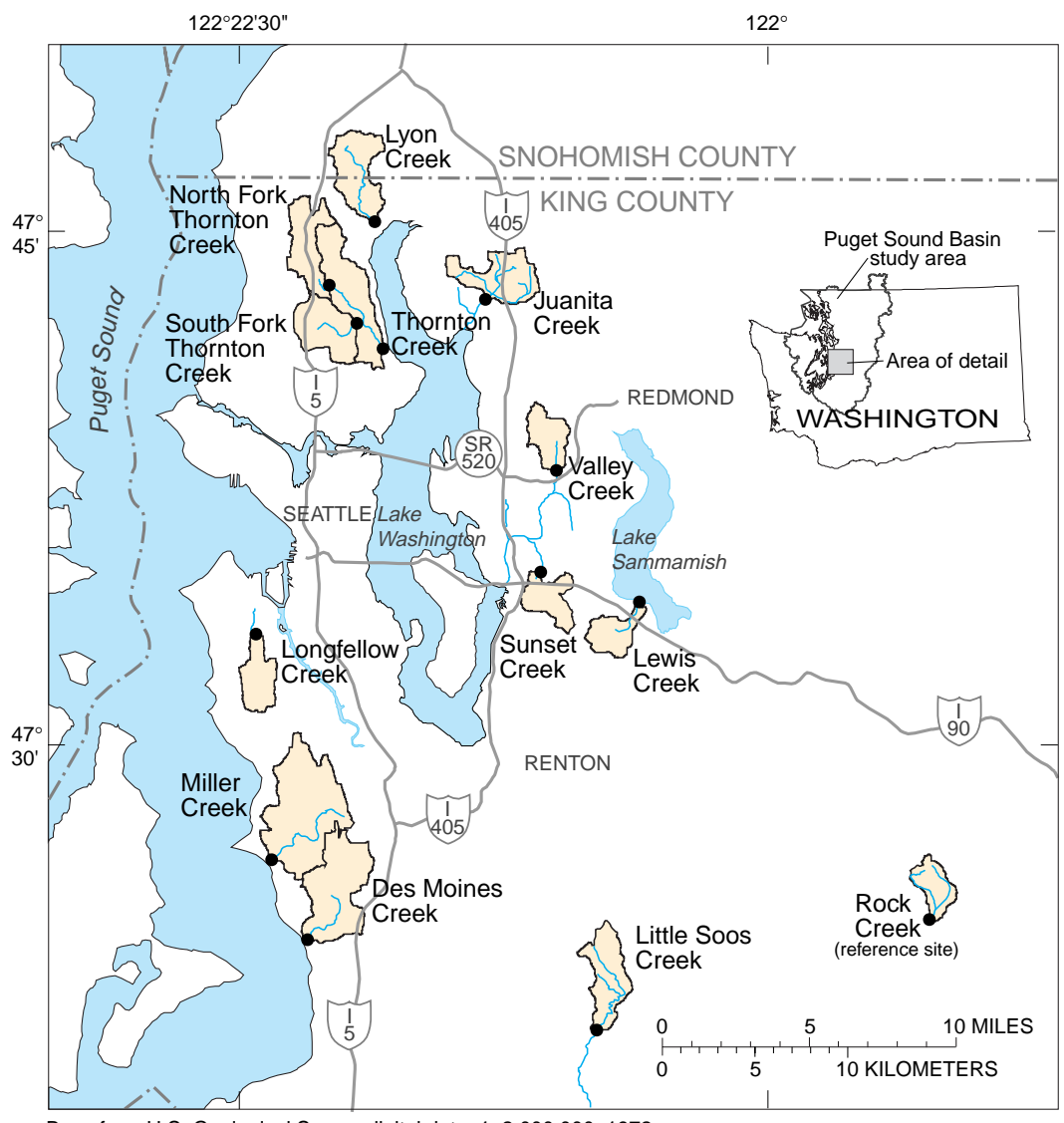

Base from U.S. Geological Survey digital data, 1: 2,000,000, 1972 Albers Conic Equal-Area Projection

Figure 1. Location of sampling sites within watersheds.

\section{Study Design}

The study was designed to detect the largest number of pesticides likely to be transported in surface runoff to urban streams. Sampling occurred when pesticide applications to residential areas were high and when transport of pesticides to surface water would be likely. Sampling was conducted in April and May because data from home and garden stores indicate that pesticide application rates are higher in April and May than in any other months during the year.
Sampling was conducted during storms because previous sampling at Thornton Creek by the USGS showed that pesticide runoff is greatest during storms. Pesticides are not only more likely to be found during storms, but the concentrations of the pesticides found are also more likely to be of ecological concern.

From two to four surface-water samples were collected at each of 12 study sites in 10 urban or suburban watersheds in King County (fig. 1). Rock Creek, in an undeveloped basin, was sampled as a reference site.

\section{Findings}

Twenty-three pesticides were detected in water from urban streams during rainstorms, and the concentrations of five of these pesticides exceeded limits set to protect aquatic life.

During rainstorms, 23 of 98 pesticides sampled for were detected in water samples from 12 study sites in 10 urban watersheds. Concentrations of five insecticides exceeded recommended maximum concentrations set by the National Academy of Sciences and National Academy of Engineering (NAS/NAE) (1973). In a few samples, concentrations of Diazinon, carbaryl, and Lindane exceeded U.S. Environmental Protection Agency (USEPA) and other chronic aquatic-life criteria.

Pesticides used on lawns and gardens contribute to the occurrence of several pesticides in urban streams.

According to 1997 sales data from home and garden stores, of the pesticides sampled for, Diazinon, 2,4-D, and MCPP are the most frequently purchased pesticides by residents of King County. MCPP and 2,4-D are also among those pesticides used by professional applicators for pest control in residential, recreational, and industrial areas. The presence of these pesticides in water samples from all of the 12 study sites shows that their widespread application impacts water quality in urban streams. Also, residents purchased and applied four of the five pesticides that exceeded recommended maximum concentrations set by the NAS/NAE (Diazinon, carbaryl, Malathion, and chlorpyrifos).

Many pesticides found in urban streams might be the result of nonresidential applications.

Almost half of the 23 pesticides detected in stream water had no retail sales according to a 1997 survey of pesticides sales from home and garden stores in King County. Two of these pesticides (atrazine and simazine) were found at more than 60 percent of the study sites. This indicates that these pesticides are being applied to nonresidential areas in urban watersheds such as rights-of-way, parks, and recreational areas. 


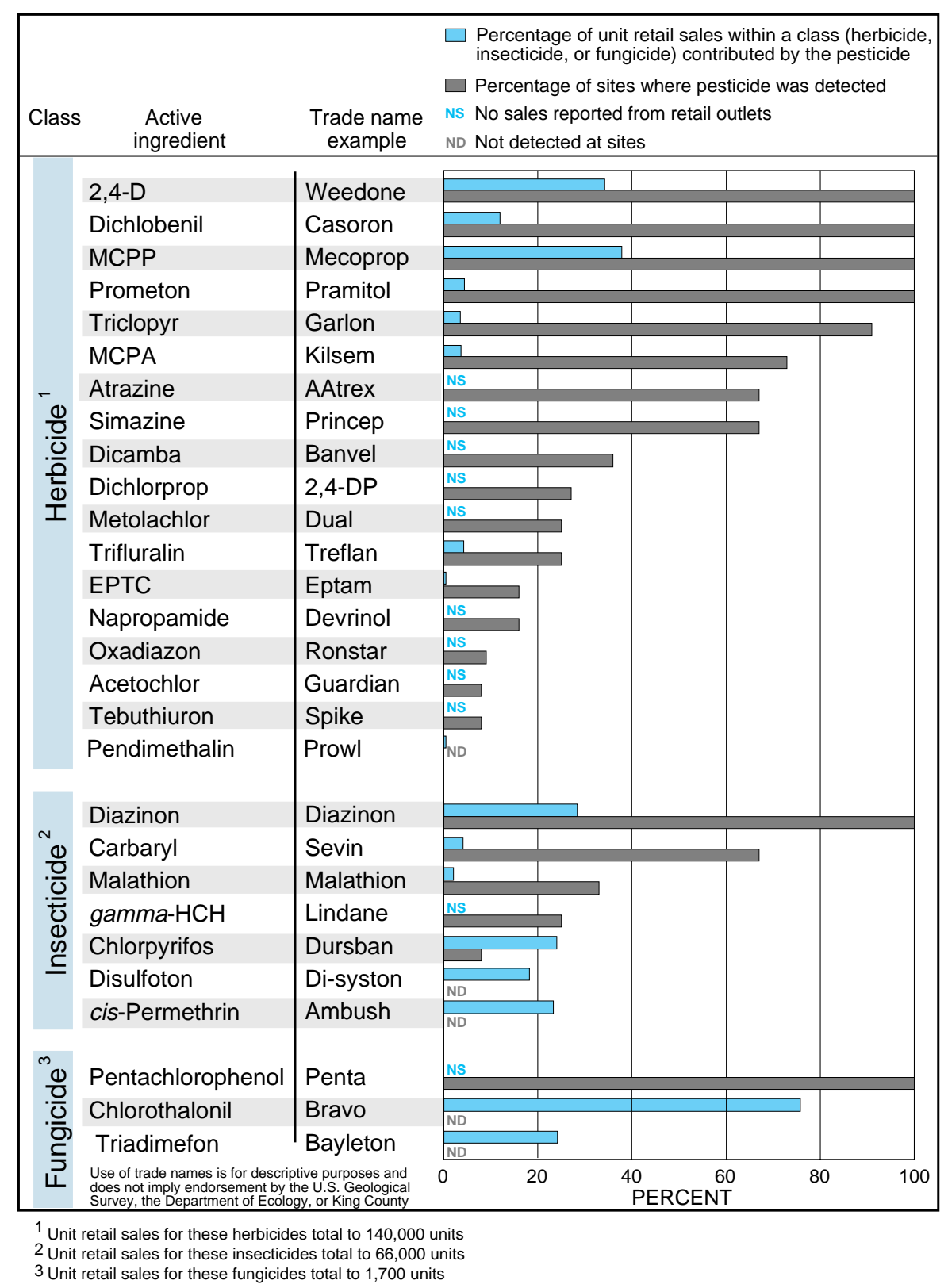

Figure 2. Percentage of unit retail sales in each pesticide class contributed by each pesticide and percentage of sites where pesticide was detected. Sales data for pesticides not analyzed for are not included.

The U.S. Geological Survey National Water Quality Laboratory and the Washington State Department of Ecology Manchester Environmental Laboratory analyzed the samples for 98 pesticides or pesticide break-down products. King County Department of Natural Resources Environmental Laboratory tested water samples from one urban site, Lyon Creek, and the reference site, Rock Creek, for toxicity.

\section{Description of Retail Sales Data}

The 1997 pesticide sales data used in this study were obtained from 10 home and garden stores located in urban and suburban areas in King and south Snohomish
Counties. The measured quantity was a "unit" or package of pesticide sold. Amounts of active ingredient applied cannot be calculated from the sales data because packages vary in size and in concentration of active ingredient. However, the numbers of packages sold indicate consumer preference and thus are some indication of how widely the active ingredient is distributed in residential areas of urban watersheds. We estimate that the sales data from the 10 home and garden stores represent consumer buying patterns throughout King County because over two-thirds of retail sales are from hardware stores (which includes home and garden stores) according to a 1996 survey of 1,200 King County residents (Market Trends Incorporated, 1996).
A complete picture of consumer buying patterns of active ingredients is not possible because of omissions in the database. Although packages of pesticides can have more than two active ingredients, only the first two active ingredients listed on the product were recorded in the home and garden store database. This means that more units were sold than recorded for some active ingredients.

For example, the database contains no reported sales of dicamba, which is occasionally the third ingredient listed in combined fertilizer-pesticides types of products.

\section{Retail Sales Data Help Identify Sources of Pesticides}

The relations between pesticides sold at home and garden stores and pesticides found in urban stream water provided information about the source of pesticides in streams. The two herbicides (2,4-D and MCPP) and the one insecticide (Diazinon) with the largest unit sales were detected at 100 percent of the sampling sites (fig. 2). These purchase rates imply that residential applications probably contribute to the presence of these three pesticides in the streams. Residential applications are a possible source of other frequently detected pesticides (such as dichlobenil and chlorpyrifos) that also have relatively high unit sales.

Pesticides that were detected at study sites but have no retail sales are probably from applications to nonresidential areas. No sales were reported for several pesticides detected at more than 20 percent of the study sites, either because they were not sold in retail outlets or were not included in the 1997 sales data (fig. 2). Detections of some of these pesticides (for example, atrazine and simazine) could result from nonresidential applications. Similarly, detections of pesticides with small numbers of units sold (prometon, triclopyr, MCPA) might be more the result of nonresidential rather than residential applications. Detections of pesticides with little or no reported retail sales could still result, in part, from residential use if one or more active ingredients in mixed formulations were not reported. For example, dicamba does not appear on the unit-sales list (fig. 2) because only the first two active ingredients were reported for each product. Dicamba, detected at nearly 40 percent of the study sites, is the third active ingredient listed in some combined fertilizer-pesticide products that are sold in home and garden stores.

Although basic relations between pesticide applications and pesticides detected in urban streams were found, other relations could not be determined from the data. For 
example, amounts of a pesticide applied by residential applicators could not be estimated and related to concentrations detected in streams because the amount of active ingredient in a unit could not be determined. Several of the pesticides sold in home and garden stores (2,4-D, MCPA, MCPP, chlorpyrifos, Malathion) are also used for pest control around structures, along rightsof-way (highways, roads and railroads), and in industrial and recreational areas (Larson and others, 1996). Therefore, the sales data cannot specifically differentiate between sources of some pesticides. It should be noted too that this study did not analyze for about 50 percent of the pesticides sold in the home and garden stores and the sales of some, like the herbicide glyphosate, were large.

Pesticides sold in retail outlets, but not detected in stream water include the insecticides disulfoton and cis-permethrin, and the fungicides chlorothalonil and triadimefon. Factors affecting the relations between sales data and pesticide detections include chemical properties of the pesticides (some degrade rapidly), usage, timing of applications, and proximity of treated areas to the streams. Further studies would need to be conducted to understand these complex interactions.

\section{Environmental Significance}

Fourteen of the pesticides detected in this study have maximum recommended concentration limits for protection of aquatic life established by the NAS/NAE (1973), or the Ministers of Health Canada and Environment Canada (1995). The limits were exceeded by sample concentrations of five insecticides--carbaryl, chlorpyrifos, Diazinon, Lindane, and Malathion (fig. 3). Eleven of the pesticides detected in this study have chronic aquatic life criteria recommended by Norris and Dost (1991), the U.S. Environmental Protection Agency (1998), and others. These limits were exceeded by concentrations of Lindane, Diazinon, and carbaryl. The aquatic-life criteria indicate concentrations that can adversely affect aquatic organisms. However, the ecological effects in the streams sampled are unknown because the duration of exposure to concentrations observed and the combined effects of many pesticides in stream water are unknown.

In addition to chemical analyses, water samples from Lyon Creek were tested for toxicity. These samples showed chronic toxicity to two organisms--Ceriodaphnia dubia, a small nearly microscopic animal, and Selenastrum capricornutum, a microscopic plant. In comparison, water samples from the reference site, Rock Creek, had no toxic effects on these organisms and no pesticide detections. Because only unfiltered water samples affected the organisms, toxicity might be due to pesticides and other chemicals sorbed to particulate matter present in the samples. Although concentrations of three pesticides in Lyon Creek samples exceeded aquatic life criteria, the sample water is a complex mixture of a variety of chemicals and further testing would have been needed to find the exact cause of the toxicity. However, these test results become important because the presence of toxicity in a water body violates State standards for surface-water quality (State of Washington, 1992).

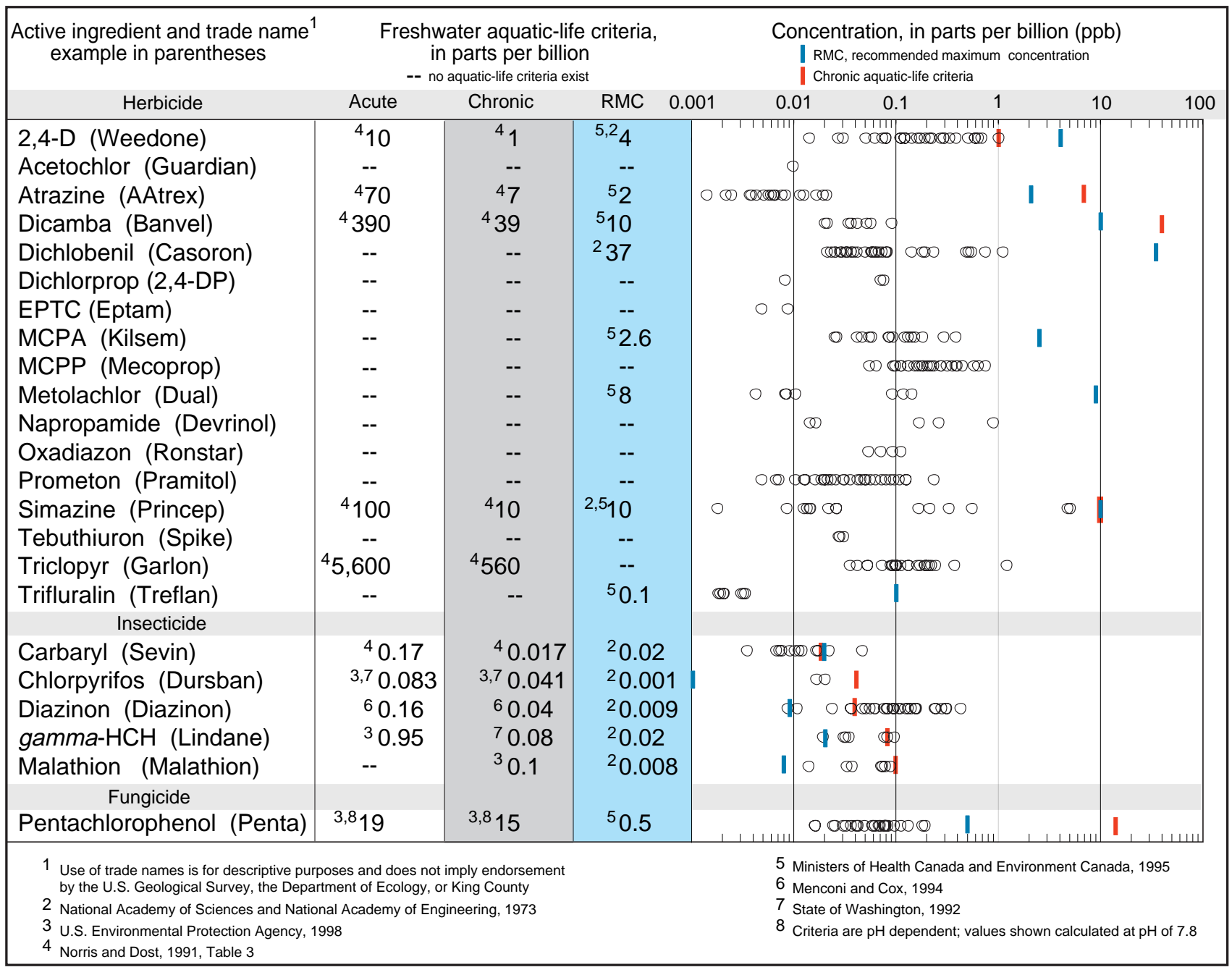

Figure 3. Concentrations of pesticides detected in water and aquatic-life criteria. 


\section{Data Availability and Additional Analysis}

Data on the concentrations of pesticides found in streams sampled during this study and a complete list of target pesticides can be obtained from the Puget Sound Basin NAWQA web site at http://wa.water.usgs.gov/ps.nawqa.html. Additional analysis of the spatial distribution of pesticides in urban watersheds and factors contributing to pesticide transport will be published in a future report by the Puget Sound Basin NAWQA team.

\section{References}

Bortleson, G.C., and Davis, D.A., 1997, Pesticides in selected small streams in the Puget Sound Basin, 1987-1995: U.S. Geological Survey Fact Sheet 067-97, 4 p.

Health Canada and Environment Canada, 1995, Canadian water guidelines--summary of guidelines for water quality in Canada: Ottawa, Ontario, Canada, Minister of Supply and Services Canada, 7 p.

\section{₹USGS}

Frank D. Voss, Sandra S. Embrey, and James C. Ebbert, U.S. Geological Survey

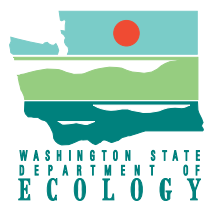

Dale A. Davis, Washington State Department of Ecology

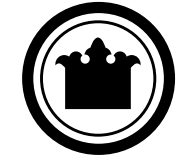

Annette M. Frahm and George H. Perry, King County Hazardous Waste KING COUNTY Management Program
Larson, S.J., Capel, P.D., and Majewski, M.S., 1996, Pesticides in surface waters-distribution, trends, and governing factors: Chelsea, Mich., Ann Arbor Press, Pesticides in Hydrologic System series, v. 3, 373 p.

Market Trends Incorporated, 1996, 1996 King County household hazardous waste survey report: Bellevue, Wash., prepared for King County Local Hazardous Waste Management Program, 74 p.

Menconi, M., and Cox, C., 1994, Hazard assessment of the insecticide diazinon to aquatic organisms in the Sacramento-San Joaquin River System: California Department of Fish and Game, Environmental Services Division, Administrative Report 94-2, 60 p.

National Academy of Sciences and National Academy of Engineering, 1973, Water quality criteria, 1972, a report of the committee on water quality criteria: Washington, D.C., Environmental Studies Board, National Academy of Sciences, National Academy of Engineering, 594 p.

\section{For further information contact:}

Project Chief, U.S. Geological Survey Puget Sound Basin NAWQA, 1201 Pacific Avenue, Suite 600, Tacoma, WA 98402 (253)428-3600

E-mail: nawqa_puget_wa@usgs.gov WWW: http://wa.water.usgs.gov/ ps.nawqa.html

Library, King County Hazardous Waste Management Program, 130 Nickerson, Suite 100, Seattle, WA 98109

(206)689-3051

E-mail: hazwaste@metrokc.gov

Acknowledgments:

Banner: Karen A. Lonsdorf

Editing: John Clemens

Illustrations: Connie Dean

Layout: Ginger Renslow
Norris, L., and Dost, F., 1991, Proposed surface water quality criteria for selected pesticides used for forest management and management of forest tree seedling and christmas tree plantations in Oregon and Washington (draft): Corvallis, Oregon, Oregon State University, 39 p.

State of Washington, 1992, Water quality standards for surface waters in the State of Washington: Olympia, Wash., chap. 173201 WAC, 14 p.

Tetra Tech Incorporated, 1988, Pesticides of concern in the Puget Sound Basin--a review of contemporary pesticide usage: Seattle, Wash., prepared for U.S. Environmental Protection Agency, Region 10, contract TC3338-32, 97 p.

U.S. Environmental Protection Agency, 1998, National recommended water quality criteria; Notice; Republication: Washington, D.C., U.S. Environmental Protection Agency, Federal Register, part IV, v. 63, no. 237, December 10, 1998, 12 p.

\section{National Water Quality Assessment (NAWQA) Program}

The National Water Quality Assessment (NAWQA) Program of the U.S. Geological Survey is designed to describe the current water-quality conditions for much of the Nation's water resources, describe changes in water quality over time, and improve understanding of the natural and human factors that affect water quality. 